\title{
Evaluation of miR-21 Expression Level in Helicobacter pylori-Infected
}

\section{Gastric Mucosa}

\author{
Mona Noohi ${ }^{1}$, Mojdeh Hakemi-Vala (iD ${ }^{2,}{ }^{,}$, Jamileh Nowroozi ${ }^{3}$, Seyed Reza Fatemi ${ }^{4}$ and Mehrouz \\ Dezfulian $^{1,5}$ \\ ${ }^{1}$ Department of Microbiology, Karaj Branch, Islamic Azad University, Karaj, Iran \\ ${ }^{2}$ Department of Microbiology, Medical School, Shahid Beheshti University of Medical Sciences, Tehran, Iran \\ ${ }^{3}$ Department of Microbiology, North Tehran Branch, Islamic Azad University, Tehran, Iran \\ ${ }^{4}$ Gastroenterologist and Hepatologist, Shahid Beheshti University of Medical Sciences, Tehran, Iran \\ ${ }^{5}$ Biotechnology Research Center, Karaj Branch, Islamic Azad University, Karaj, Iran \\ "Corresponding author: Department of Microbiology, Medical School, Shahid Beheshti University of Medical Sciences, Tehran, Iran. Email: mojdeh_hakemi@yahoo.com
}

Received 2020 May 05; Revised 2020 August 09; Accepted 2020 August 30.

\begin{abstract}
Background: Gastric cancer is one of the main causes of death worldwide. In this regard, Helicobacter pylori infection is considered as the main risk factor for gastric cancer. MicroRNA (mirNA) can interface with mRNA molecules as well as blocking their translation into proteins or inducing degradation.

Objectives: The aim of this study was to compare the expression of mir-21 in biopsy samples of gastritis and healthy adjacent tissues. Methods: Between Feb-Dec 2017, 70 patients with dyspeptic symptoms from Taleghani Hospital were enrolled in this study. Accordingly, the expression level of mir-21 was evaluated using semi-quantitative RT-PCR in mucosal biopsy samples from those wellcharacterized patients. Moreover, the U6 gene was used as an internal control.

Results: Our data indicated that mir-21 expression was significantly up-regulated in the infected samples with $H$. pylori compared to healthy samples.

Conclusions: Our results confirm that $\mathrm{H}$. pylori infection can alter the expression of mir-21 in gastric epithelial cells and gastric mucosal tissues. However, the exact role of the miRNA changes in H. pylori infection will require further experiments.
\end{abstract}

Keywords: Helicobacter pylori, mir-21, RT-PCR, Gastritis

\section{Background}

Helicobacter pylori is one of the most prevalent human pathogens, contributing to some gastrointestinal related diseases such as gastritis, peptic ulcer, and gastric cancer (1). Over $50 \%$ of people are silent carriers of $H$. pylori, hence it has been defined as type I carcinogen in terms of the WHO classification (2). Gastric cancer is ranked as the fourth common cancer, and is also the second mortality cause worldwide (3). The bacteria secrete urease to neutralize the acidic condition of gastric mucosa, which then adheres to the cellular surface via blood-antigen binding protein $\mathrm{A}(B a b A)$ and sialic acid-binding adhesion $\mathrm{A}(\mathrm{SabA})$ contributing to tissue damage by releasing several toxins such as cytotoxin-associated gene A (CagA) and vacuolating cytotoxin $\mathrm{A}(\operatorname{Vac} A)(4)$. Accordingly, VacA is presented in all strains contributing to the apoptosis and suppression of the T and B-lymphocytes proliferation, which finally result in chronic infection. Also, it induces the production of radical oxygen species (ROS) leading to mitochondrial
DNA mutation in gastric mucosa (5).

Notably, CagA is presented in approximately $60 \%$ of $H$. pylori strains, which promotes severe gastritis, ulcer, and gastric cancer. Moreover, it disturbs the apical-junctional function through the interaction with tight-junction scaffolding protein ZO-1 (6). In addition, it enhances $N F-\kappa B$ pathways by interacting with TNF-receptor associated factor 6 (TRAF6) and TFG-B activating kinase, which consequently result in a higher level of interleukin-8 (IL-8) production. CagA also has some properties such as methylation of MGMT DNA repair gene as the epi-genic regulator, interfering with tumor suppressor $R U N \times 3$, and TP53 degradation with proteasome $(7,8)$. However, only some colonized bacteria may ever develop neoplasia and cancer, suggesting that the progression to cancerous type depends on several factors such as strain-specific bacteria, virulence factors, host response, and environmental factors (7).

MicroRNAs (miRNAs) are 18 - 28 base pair noncoding RNAs that regulate target gene expression through degra- 
dation or translation inhibition of mRNA (9). In bioinformatics studies, several miRNAs have been identified in the human genome. Correspondingly, it is estimated that about $30-92 \%$ of human genes are regulated by miRNAs (10, 11). They play important roles in apoptosis, cell proliferation, and differentiation. Since miRNAs play a major role in the expression of tumor suppressor genes and oncogenes involving in the proliferation and apoptosis, it also contributes to the initiation and progression of malignancy (12). In the case of any gastric cancer, some miRNAs are down-regulated, which results in tumor suppression while others like mir-21 are overexpressed in gastric mucosa indicating to oncogenes (13). Although some studies demonstrated the relationship between miRNAs and gastric cancer, these data could not be generalized for all the regions of the world, as the pattern of disease differs according to ethnic and spatial localization of people worldwide. Moreover, the effect of mirNAs on the progression of gastric cancer has been evaluated in Iran, but there is no data indicating that these markers are presented since the beginning of $H$. pylori infection. Accordingly, this later contributes to neoplasia or some other factors may affect the expression of miRNA at neoplasia of gastric related to H. pylori.

\section{Objectives}

In the current study, the expression of mir-21 in biopsy samples of gastritis has been evaluated compared to healthy adjacent part of endoscopic candidates referring to the Taleghani Hospital.

\section{Methods}

\subsection{Patients}

Seventy patients who were referred to the Taleghani Hospital diagnosed with dyspeptic symptoms by a specialist between February and December 2017, were enrolled in this study. Demographic characteristics of these patients and their lifestyles such as smoking, diets, and history of disease were separately recorded (Table 1 ).

\subsection{Endoscopy and Biopsy Collection}

Endoscopy was performed by gastroenterologists and five biopsy samples ( 4 from gastritis parts of antrum and 1 from adjacent healthy part) were subsequently taken. One tissue sample was embedded in paraffin for performing pathological evaluation and the presence of $H$. pylori was confirmed by Giemsa staining of the paraffin-embedded blocks. The endoscopic findings were described as normal, gastritis, and gastric ulcer. Three other biopsy samples were immediately transferred to the laboratory in a

\begin{tabular}{|lc}
\hline Table 1. Demographic and Clinical Characteristics of Patients with Pyelonephritis \\
\hline Characteristic & Values \\
\hline Mean age & $48.50 \%(18-83)$ \\
\hline Sex & $32(45.7)$ \\
\hline Male & $38(54.3)$ \\
\hline Female & $21(30)$ \\
\hline Smokers & $19(27.1)$ \\
\hline Canned food consumption & $18(27.7)$ \\
\hline non-consumer & $9(12.9)$ \\
\hline Once in a month & $11(15.7)$ \\
\hline Twice in a month & $13(18.6)$ \\
\hline Once in a week & \\
\hline Twice in a week & $8(11.4)$ \\
\hline Underlying disease & $33(47.1)$ \\
\hline Heart diseases & $5(7.1)$ \\
\hline Gastric diseases & $7(10)$ \\
\hline Diabetes & \\
\hline Respiratory diseases & \\
\hline
\end{tabular}

${ }^{\mathrm{a}}$ Values are expressed as No. (\%).

transfer media, to culture and analyze the molecular characteristic. The fifth biopsy, as the healthy adjacent part, was administered as a control sample. Simultaneously, $5 \mathrm{~mL}$ of each blood sample from the participants was collected on EDTA.

\subsection{Helicobacter pylori Culture and Identification}

One of the fresh gastric biopsy sample was homogenized and then cultured on Brucella agar (Merck, Germany) media containing vancomycin (6 mg/L), TMP (5 $\mathrm{mg} / \mathrm{L}$ ), and fungizone $(2 \mathrm{mg} / \mathrm{L}$ ) (all antibiotics purchased from Sigma Chemical Co., St.Louis, Mo.). Afterward, the inoculated plates were incubated for $3-5$ days at $37^{\circ} \mathrm{C}$ under a microaerophilic condition using $\mathrm{CO}_{2}$ gas pack type C (Anaerocult C, Merck, Germany). Subsequently, colonies were transferred to Brucella blood agar with no antibiotics after the first passage and incubated for another $48-72$ hours at $37^{\circ} \mathrm{C}$ under a microaerophilic condition (Anerobic jar and gas pack type C). Based on the reference protocol, to confirm the $H$. pylori identification, the oxidase, catalase tests, and Gram staining were performed (14).

\subsection{DNA Extraction}

DNA extraction was performed using the boiling method on the confirmed bacteria colonies (15). One of the remained gastric biopsy sample was homogenized for DNA extraction of bacteria using the Stratec molecular kit 
(Berlin, Germany) in terms of the manufacture's structure. Also, DNA extraction was done on the blood samples using a similar method. The OD of the extracted DNA samples was detected by a Nanodrop instrument (DeNovix, USA) at $260 \mathrm{~nm}$ and then stored at $-20^{\circ} \mathrm{C}$ until analysis.

\subsection{Helicobacter pylori Identification by PCR}

The presence of $H$. pylori according to molecular analysis was determined using the $H$. pylori PCR detection kit (Cinnagen co, Tehran. Iran) in terms of the following procedure; $1 \times$ PCR mix, Tag DNA polymerase, and DNase free deionized sterile water. Also, DNA samples were then amplified using the following program: Initial denaturation for $45 \mathrm{sec}$ at $94^{\circ} \mathrm{C}$, for $20 \mathrm{sec}$ at $50^{\circ} \mathrm{C}$, and for $20 \mathrm{sec}$ at $72^{\circ} \mathrm{C}$ with 5 cycle repeat following 30 cycle for $20 \mathrm{sec}$ at $94^{\circ} \mathrm{C}$, annealing for $20 \mathrm{sec}$ at $50^{\circ} \mathrm{C}$, and the final extension for $30 \mathrm{sec}$ at $72^{\circ} \mathrm{C}$. The presence of $492 \mathrm{bp}$ in $1 \%$ agarose gel indicated the positive samples for $H$. pylori.

Helicobacter pylori-positive samples were amplified with specific primers of the CagA gene (Metabion, Germany) to determine the invasive form of $H$. pylori (Table 2 ). In addition, PCR was carried out in a final volume of $25 \mu \mathrm{L}$ containing $12.5 \mu \mathrm{L}$ of Taq PCR Master Mix (Qiagen, Hilden, Germany), $2 \mu \mathrm{L}(0.5 \mu \mathrm{g} / \mu \mathrm{L})$ of template DNA, 1.0 $\mu \mathrm{L}(1 \mu \mathrm{M})$ of each primer, and $8.5 \mu \mathrm{L}$ of PCR-grade distilled water (provided with the Taq PCR Master Mix). Amplification was performed as follows: an initial denaturation step for $4 \mathrm{~min}$ at $94^{\circ} \mathrm{C}$, followed by 35 cycles, which included denaturation for $1 \mathrm{~min}$ at $94^{\circ} \mathrm{C}$, primer annealing for $1 \mathrm{~min}$ at $59^{\circ} \mathrm{C}$, and extension for $1 \mathrm{~min}$ at $72^{\circ} \mathrm{C}$. Finally, an extension step was performed for $10 \mathrm{~min}$ at $72^{\circ} \mathrm{C}$. A negative control (without template DNA) was included in each run. PCR products (397 bp) were separated by electrophoresis using $2 \%$ agarose gel run in Tris acetate-EDTA (TAE) buffer and stained with ethidium bromide. The gel was visualized under ultraviolet transillumination. Also, a molecular size marker $100 \mathrm{bp}$ DNA ladder (Cleaver Scientific, UK) was used to determine the size of the bands.

\begin{tabular}{lcc}
\hline \multicolumn{1}{l}{ Fable 2. List of Primers } & \\
\hline & CTCGCTTCGGCAGCACATATACT & ACGCTTCACGAATTTGCGTGTC \\
\hline U6 gene & Reveres \\
CagA gene & AATACACCAACGCCTCCAAG-3' & TTGTTGCCGCTTGCTCTC \\
Mir-21 gene & GCTTATCAGACTGATGTTGACTG & CAGCCCATCGACTGGTG
\end{tabular}

\subsection{RNA Extraction and Detection of mir-21}

Micro RNA was extracted from the gastric biopsy samples using Bio basic kit (Canada inc, kit) in terms of the manufacturer's instruction. Moreover, DNase (deoxyribonuclease) was administered to remove any any contamination of DNA from the extracted RNA, which was carried out in total volume 10 microliter containing $1 \lambda \mathrm{MgCl}_{2}$, 0.5 $\lambda$ DDNase, extracted RNA, and DEPC water. Afterward, they were incubated for $30 \mathrm{~min}$ at $37^{\circ} \mathrm{C}$ following by an incubation for $10 \mathrm{~min}$ at $65^{\circ} \mathrm{C}$ after the addition of $1 \lambda$ EDTA. As the RNA is unstable, cDNA was immediately synthesized using Maxime RT PreMix (oligo DT primer.iNTron, Korea). Accordingly, the protocol was carried out according to the manufacturer's structure. Detection of mir-21 was performed using real Q plus $2 \times$ Master Mix Green, without using ROX Kit (AmpliQon, Denmark) according to the standard protocol, which was carried out in a total volume $23 \lambda$ with $12.5 \lambda$ master mix cyber green NO ROX, $2 \lambda$ forward and reverse primers, $8.5 \lambda \mathrm{DEPC}$ water. The real-time program was performed as follows: initial denaturation for 5 min at $95^{\circ} \mathrm{C}$, following 25 cycles with denaturation for 20 sec at $95^{\circ} \mathrm{C}$, annealing for $30 \mathrm{~s}$ at $60^{\circ} \mathrm{C}$, and extension for $20 \mathrm{~s}$ at $72^{\circ} \mathrm{C}$. Quantitative real-time data were analyzed using $2^{-\Delta \Delta \mathrm{CT}}$ method. Also, the mir-21 was amplified with U6 gene as an internal control. Primers sets for each gene are listed in Table 2.

\subsection{Statistical Analysis}

All statistical analyses were performed using SPSS 18.0 software (SPSS Inc, Chicago, and IL., USA). The chi-square $\left(\chi^{2}\right)$, one-way ANOVA test, and odds ratio were determined for the $H$. pylori presence and histopathological finding. The correlation of gene expression, type of gastric diseases, and the subjects' lifestyle, were analyzed using unpaired $t$ test. A P value less than 0.05 was considered as statistically significant.

\section{Results}

The demographic characteristics of the patients as well as the source of their infection were documented. The results show that $54.3 \%$ and $45.7 \%$ of the participants were female and male, respectively, with the mean age of $50.53 \pm$ 16.91 years old. Moreover, the lifestyle habits such as smoking, diets, and history of disease for each patient are shown in Table 2. About 10 out of 50 samples were successfully isolated from Brucella blood agar (Figure 1). The frequency of positive $H$. pylori culture was $14 \%$ (10/70). Also, pathology examinations showed that 32 (45.7\%) participants were infected by $H$. pylori (Figure $2 \mathrm{~A}$ and B). Also, 74.3\% and $57.1 \%$ of the participants were suffering from gastritis and reflux, respectively. 


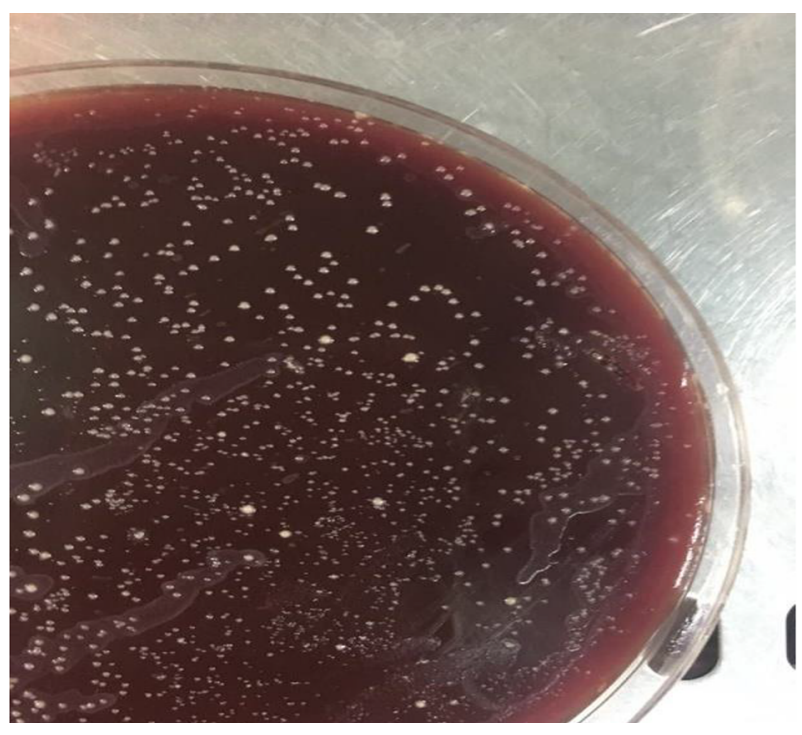

Figure 1. Positive culture of Helicobacter pylori on Brucella blood agar media

\subsection{Helicobacter pylori Identification and CagA Gene by PCR}

The results of PCR product of $H$.pylori identification kit are shown in Figure 3. Also, the CagA gene of PCR product in $1.5 \%$ agarose gel is shown in Figure 4.

\subsection{Expression of mir-21 in Unhealthy and Healthy Tissue Sam- ples}

The miRNA RT-qPCR experiments were carried out on antrum biopsy samples and the adjacent healthy samples obtained from the participants, which showed that the expression level of mir-21 was significantly higher in the infected samples compared to the healthy samples $(\mathrm{P}<$ 0.001) (Figure 4). Thus, our data confirmed that, mir-21 expression was significantly up-regulated in the infected samples with $H$. pylori compared to the healthy samples.

Expression of mir-21 in the blood of the patients infected with $H$. pylori and healthy subjects real-time PCR analysis showed that the mir-21 level was numerically upregulated compared to the $H$. pylori-positive and $H$. pylorinegative tissues. However, it was not statistically significant (Pvalue $>0.05)$.

\section{Discussion}

Although deregulation of many miRNAs has been recently documented in various diseases extensively, the correlation between chronic bacterial infections and alteration in the expression level of miRNAs still is a challenging issue for researchers. Recently, some authors reported that $H$. pylori can affect the expression of various miRNAs, which may mediate the epigenetic misregulation of oncogenes and tumor suppressor genes as well as illustrating the bridge between $H$. pylori infection and gastric cancer $(16,17)$. Accordingly, a study conducted by Matsushima et al. (14) aimed to characterize the expression patterns of diverse miRNAs in gastric mucosa infected by $H$. pylori. Using high throughput profiling analysis, $31 \mathrm{miRNAs}$, including some members of the let-7 family, was recognized to be differentially expressed between the $H$. pylori-infected and $H$. pylori-uninfected gastric mucosa. More recently, by the use of some in vitro experiments, it was indicated that the cytotoxin-associated gene ( $\mathrm{CagA})$ of $H$.pylori can induce mir-584, mir-1290, and mir-146 $(18,19)$. Several studies have also revealed the specific alterations in the expression levels of some miRNAs in human gastric cancer compared to non-cancerous adjacent tissue $(13,20)$. The present study was designed to investigate mir-21 expression among $H$. pylori-infected compared to the healthy biopsy samples as well as the blood samples of endoscopy candidates.

In the current study, it was confirmed that mir-21 was significantly overexpressed in $H$. pylori infected samples compared to normal samples. According to these findings, mir-21 was the primary miRNA found in gastric cancer and $H$. pylori infected tissues $(21,22)$. Inflammatory cytokines, as well as NF- $\kappa B$, mediated the inactivation of AP-1 transcription, which is able to induce mir-21 that could explain mir-21 overexpression during $H$. pylori infection (7). In a study conducted by Liu et al. (22), the expression of miRNA-21 was remarkably up-regulated in sporadic gastric tumor tissues compared to the non-cancerous tissues. Shiotani et al. (23) reported a higher expression of mir-21 in metaplastic gut mucosa compared with non-metaplastic mucosa. Correspondingly, it was shown that the eradication of $H$. pylori promotes miRNA deregulation in the gastric mucosa, rather than metaplastic sites. They suggested that the long-term colonization of $H$. pylori might induce epigenetic modifications, which cannot return to its normal status with $H$. pylori eradication alone (23). The overexpression of mir-21 in gastric cancer is probably related to $H$. pylori infection, as reported by Zhang et al. (13). Therefore, it can be concluded that $H$. pylori infection can up-regulate mir-21 expression followed by the development of gastric cancer.

Similar to other studies, some advantages and limitations exist in the current study. One of the advantages of this study is the use of a healthy adjacent part of each patient, as a control, to compare the miRNA-21 expression levels. Also, the expression level of miRNA-21 was detected in the blood samples of each patient. However, the main limitation of the current study was its design that was descriptive, so a prospective cohort study should be performed to support a causal relationship among $H$. pylori 


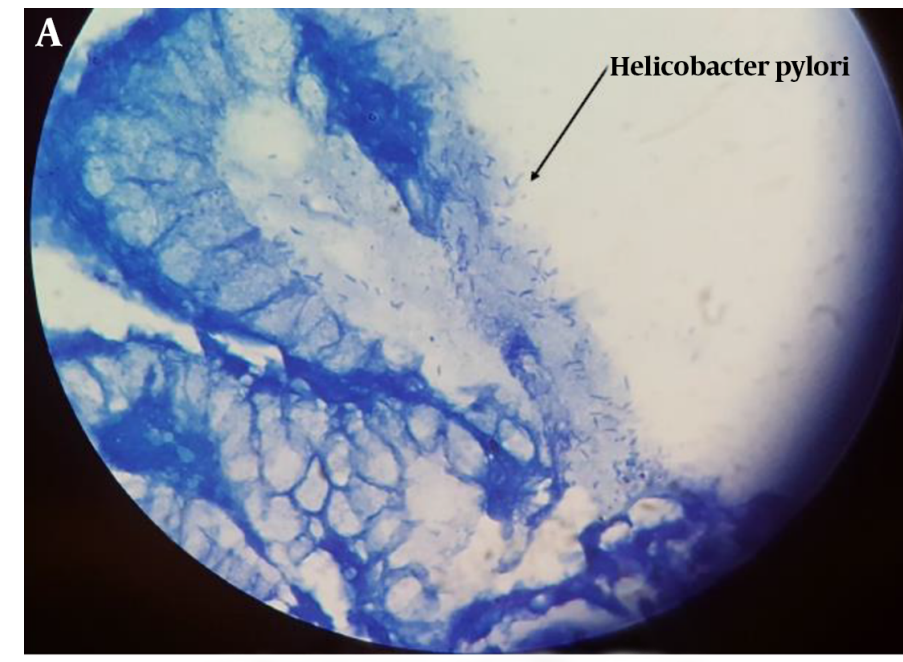

Gastric Mucosa with Helicobacter pylori

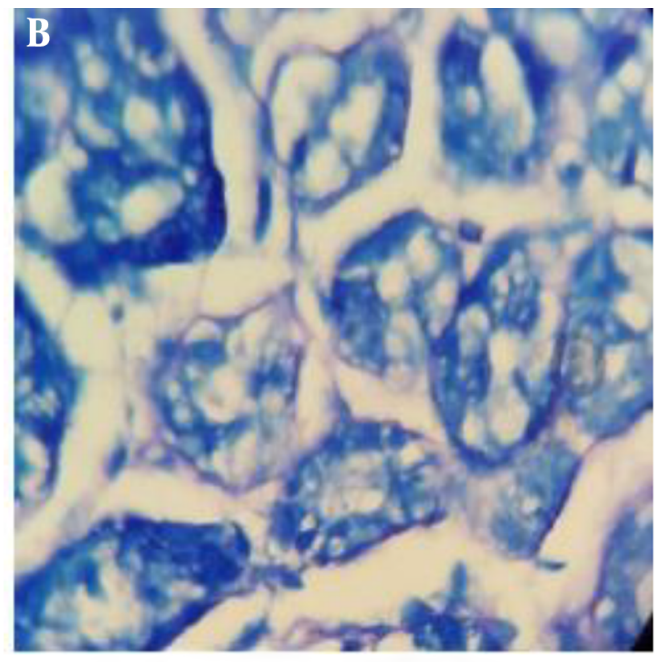

Normal Adjacent Tissue

Figure 2. Histopathological features of gastric mucosa. A, Gastric mucosa with Helicobacter pylori; B, gastric mucosa of normal adjacent part

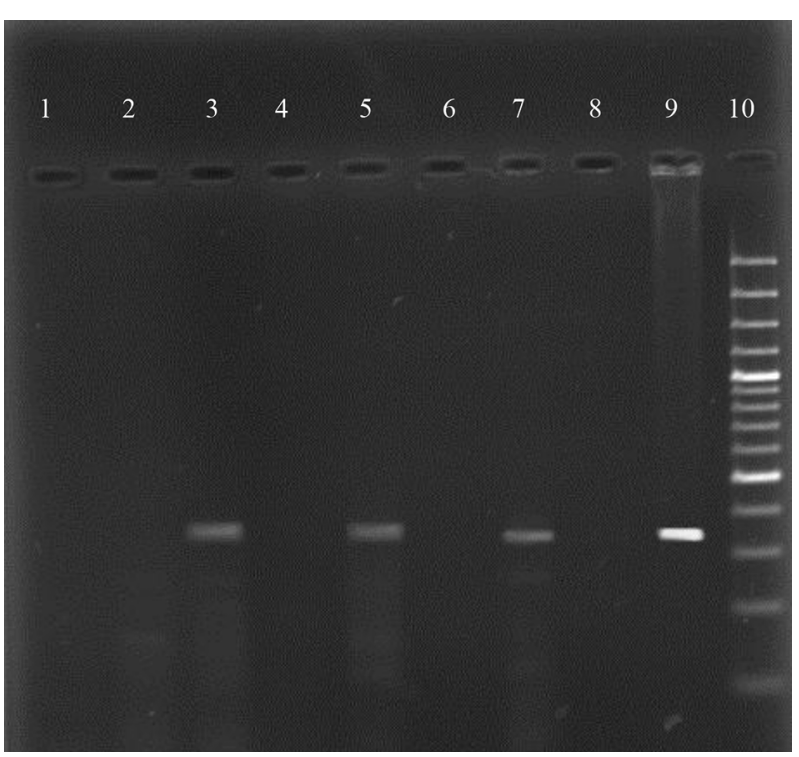

Figure 3. PCR result of CagA gene of H. pylori isolated from positive for Helicobacter pylori patients. Number $1,2,4$, and 6 , negative samples; numbers 3,5 , and 7 , positive samples; number 8, negative control; number 9, positive control; number 10, $1 \mathrm{~kb}$ DNA ladder.

infection, miRNA expression, and the subsequent risk of gastric cancer development. Another limitation was that our experiments were not performed based on microarray miRNA expression measurements and there will be a significant indication in the expression of various miRNAs related to H. pylori infection and development of gastric can- cer. Therefore, further in vitro and in vivo evaluations are required to achieve a comprehensive association among H. pylori pathogenesis, deregulation of miRNAs, and the associated abnormalities in cellular signaling in gastric cancer. Also, identification of the target genes in future studies is recommended for achieving a better understanding on the H. pylori infection and its impact on miRNA expression. Although there are some studies in this subject, most of them were done based on bioinformatics, which needs to be confirmed in vitro conditions.

\subsection{Conclusions}

In conclusion, it should be noted that $H$. pylori can alter the expression of various miRNAs in gastric epithelial cells and gastric mucosal tissues. Therefore, the altered miRNAs, especially overexpression of Oncomirs, may identify a potential link between miRNAs and pathogenesis of H. pylori-related complications. However, the way that the dysregulation of these miRNAs is involved in the pathological development of gastric cancer is not quite clear yet. So, high throughput sequencing should be performed to obtain complete descriptions of tissue miRNA dysregulation in H. pylori-related diseases.

\section{Acknowledgments}

The present article is a part of a accepted research plan and is financially supported by "Research Department of the School of the medicine, Shahid Beheshti University of 

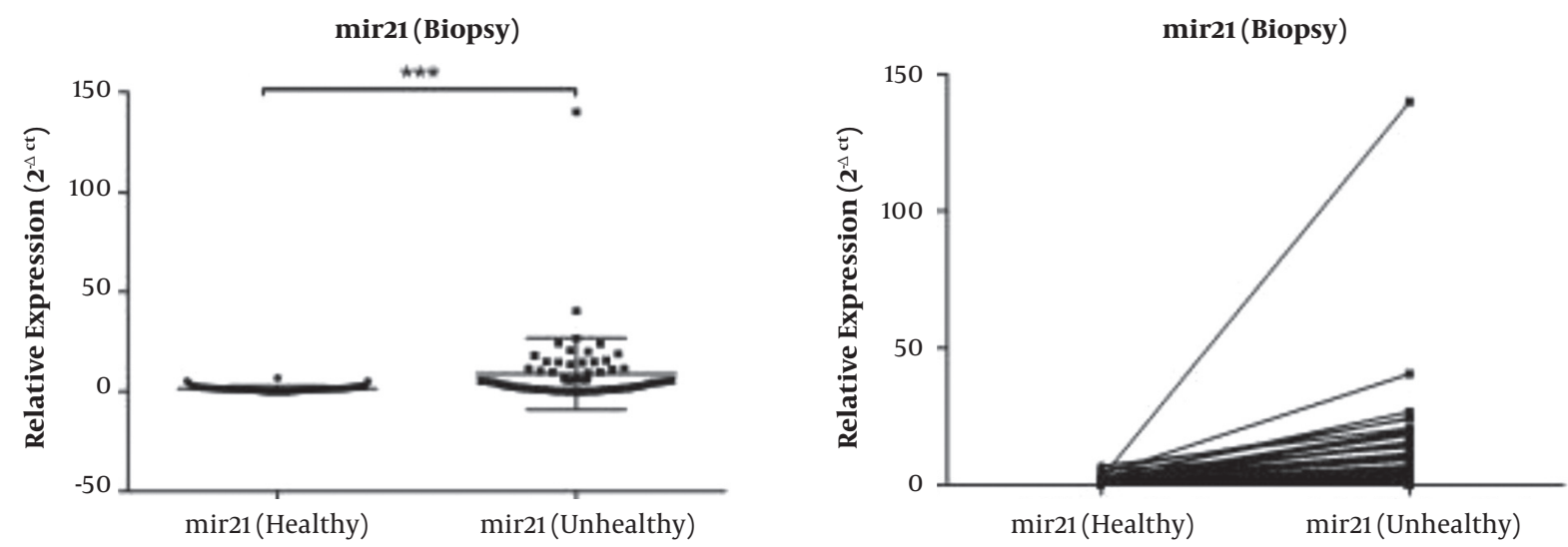

Figure 4. Comparative RT-qPCR experiments of miR-21 level in infected samples with Helicobacter pylori and healthy samples. The level of GAPDH and U6 were used as internal controls for normalization of miRNA expression. Data are reported as mean value $\pm S E(n=3)$. Student's $t$-test was used for data analysis. ${ }^{* * *}$, Represents P value $<0.001$.

Medical Sciences" (Grant No. 8975) and is approved by ethical committees of Shahid Beheshti University of Medical Sciences (Ethical No IR.SBMU.MSP.REC.1396.43).

\section{Footnotes}

Authors' Contribution: Mojdeh Hakemi Vala did administrative, technical, material support, and study supervision. Mona Noohi did analysis and interpretation of data, drafting of the manuscript, and critical revision of the manuscript for important intellectual content. Jamileh Noorouzi did study concept and design. Reza Fatemi did statistical analysis. Mehrnouz Dezfulian did administrative, technical, and material support.

Conflict of Interests: All authors declared that they have no conflict of interest.

Ethical Approval: This study was approved by ethical committees of Shahid Beheshti University of Medical Sciences with number IR.SBMU.MSP.REC.1396.43.

Funding/Support: The present article is a part of an accepted research plan and is financially supported by "Research Department of the School of the medicine, Shahid Beheshti University of Medical Sciences" (grant no.: 8975) and is approved by Ethical Committees of Shahid Beheshti University of Medical Sciences (ethical no.: IR.SBMU.MSP.REC.1396.43).

Informed Consent: All the patients signed the informed consent form prior to participation.

\section{References}

1. Cover TL, Blaser MJ. Helicobacter pylori in health and disease. Gastroenterology. 2009;136(6):1863-73. doi: 10.1053/j.gastro.2009.01.073. [PubMed: 19457415]. [PubMed Central: PMC3644425].
2. Calvet X, Ramirez Lazaro MJ, Lehours P, Megraud F. Diagnosis and epidemiology of Helicobacter pylori infection. Helicobacter. 2013;18 Suppl 1:5-11. doi: 10.1111/hel.12071. [PubMed: 24011238].

3. Ishaq S, Nunn L. Helicobacter pylori and gastric cancer: A state of the art review. Gastroenterol Hepatol Bed Bench. 2015;8(Suppl 1):S6-S14 [PubMed: 26171139]. [PubMed Central: PMC4495426].

4. Kao CY, Sheu BS, Wu JJ. Helicobacter pylori infection: An overview of bacterial virulence factors and pathogenesis. Biomed J. 2016;39(1):1423. doi: 10.1016/j.bj.2015.06.002. [PubMed: 27105595]. [PubMed Central: PMC6138426]

5. Torres VJ, VanCompernolle SE, Sundrud MS, Unutmaz D, Cover TL. Helicobacter pylori vacuolating cytotoxin inhibits activation-induced proliferation of human $\mathrm{T}$ and B lymphocyte subsets. J Immunol. 2007;179(8):5433-40. doi: 10.4049/jimmunol.179.8.5433. [PubMed: 17911630].

6. Handa O, Naito Y, Yoshikawa T. CagA protein of Helicobacter pylori: A hijacker of gastric epithelial cell signaling. Biochem Pharmacol. 2007;73(11):1697-702. doi: 10.1016/j.bcp.2006.10.022. [PubMed: 17134680].

7. Libanio D, Dinis-Ribeiro M, Pimentel-Nunes P. Helicobacter pylori and microRNAs: Relation with innate immunity and progression of preneoplastic conditions. World J Clin Oncol. 2015;6(5):111-32. doi: 10.5306/wjco.v6.i5.111. [PubMed: 26468448]. [PubMed Central: PMC4600186].

8. Lamb A, Chen LF. The many roads traveled by Helicobacter pylori to NFkappaB activation. Gut Microbes. 2010;1(2):109-13. doi: 10.4161/gmic.1.2.11587. [PubMed: 21326919]. [PubMed Central: PMC3023589].

9. Filip A. [MiRNA-new mechanisms of gene expression control]. Postepy Biochem. 2007;53(4):413-9. [PubMed: 19024905].

10. $\mathrm{Xu}$ P, Guo M, Hay BA. MicroRNAs and the regulation of cell death. Trends Genet. 2004;20(12):617-24. doi:10.1016/j.tig.2004.09.010. [PubMed: 15522457].

11. Miranda KC, Huynh T, Tay Y, Ang YS, Tam WL, Thomson AM, et al. A pattern-based method for the identification of MicroRNA binding sites and their corresponding heteroduplexes. Cell.2006;126(6):120317. doi: 10.1016/j.cell.2006.07.031. [PubMed: 16990141].

12. Cheng AM, Byrom MW, Shelton J, Ford LP. Antisense inhibition of human miRNAs and indications for an involvement of miRNA in cell growth and apoptosis. Nucleic Acids Res. 2005;33(4):12907. doi: 10.1093/nar/gki200. [PubMed: 15741182]. [PubMed Central: PMC552951]. 
13. Zhang Z, Li Z, Gao C, Chen P, Chen J, Liu W, et al. miR-21 plays a pivotal role in gastric cancer pathogenesis and progression. Lab In vest. 2008;88(12):1358-66. doi: 10.1038/labinvest.2008.94. [PubMed: 18794849].

14. Matsushima K, Isomoto H, Inoue N, Nakayama T, Hayashi T, Nakayama $\mathrm{M}$, et al. MicroRNA signatures in Helicobacter pylori-infected gastric mucosa. Int J Cancer. 2011;128(2):361-70. doi: 10.1002/ijc.25348. [PubMed: 20333682].

15. Zabaleta J. MicroRNA: A Bridge from H. pylori Infection to Gastritis and Gastric Cancer Development. Front Genet. 2012;3:294. doi: 10.3389/fgene.2012.00294. [PubMed: 23248648]. [PubMed Central: PMC3521996].

16. Taganov KD, Boldin MP, Chang KJ, Baltimore D. NF-kappaB-dependent induction of microRNA miR-146, an inhibitor targeted to signaling proteins of innate immune responses. Proc Natl Acad Sci U S A. 2006;103(33):12481-6. doi: 10.1073/pnas.0605298103. [PubMed: 16885212]. [PubMed Central: PMC1567904].

17. Zhu Y, Jiang Q, Lou X, Ji X, Wen Z, Wu J, et al. MicroRNAs upregulated by CagA of Helicobacter pylori induce intestinal metaplasia of gastric epithelial cells. PLoS One. 2012;7(4). e35147. doi: 10.1371/journal.pone.0035147. [PubMed: 22536353]. [PubMed Central: PMC3335061].

18. Kim YK, Yu J, Han TS, Park SY, Namkoong B, Kim DH, et al. Functional links between clustered microRNAs: Suppression of cellcycle inhibitors by microRNA clusters in gastric cancer. Nucleic Acids
Res. 2009;37(5):1672-81. doi: 10.1093/nar/gkp002. [PubMed: 19153141]. [PubMed Central: PMC2655672].

19. Guo J, Miao Y, Xiao B, Huan R, Jiang Z, Meng D, et al. Differential expression of microRNA species in human gastric cancer versus non-tumorous tissues. J Gastroenterol Hepatol. 2009;24(4):652-7. doi: 10.1111/j.1440-1746.2008.05666.x. [PubMed: 19175831].

20. Volinia S, Calin GA, Liu CG, Ambs S, Cimmino A, Petrocca F, et al. A microRNA expression signature of human solid tumors defines cancer gene targets. Proc Natl Acad Sci U S A. 2006;103(7):2257-61. doi: 10.1073/pnas.0510565103. [PubMed: 16461460]. [PubMed Central: PMC1413718].

21. Liu L, Chen Q, Lai R, Wu X, Wu X, Liu F, et al. Elevated expression of mature miR-21 and miR-155 in cancerous gastric tissues from Chinese patients with gastric cancer. J Biomed Res. 2010;24(3):187-97. doi: 10.1016/S1674-8301(10)60028-0. [PubMed: 23554630]. [PubMed Central: PMC3596554].

22. Liu W, Song N, Yao H, Zhao L, Liu H, Li G. miR-221 and miR-222 Simultaneously Target RECK and Regulate Growth and Invasion of Gastric Cancer Cells. Med Sci Monit.2015;21:2718-25. doi:10.12659/MSM.894324. [PubMed: 26364844]. [PubMed Central: PMC4576921].

23. Shiotani A, Murao T, Kimura Y, Matsumoto H, Kamada T, Kusunoki H, et al. Identification of serum miRNAs as novel non-invasive biomarkers for detection of high risk for early gastric cancer. Br J Cancer. 2013;109(9):2323-30. doi: 10.1086/605443. [PubMed: 19650740]. 